\title{
Results From the Mozambique 2016 Report Card on Physical Activity for Children and Adolescents
}

\author{
António Prista, Timoteo Daca, Francisco Tchonga, Eduardo Machava, Cremildo Macucule, \\ and Edmundo Ribeiro
}

\begin{abstract}
Background: This article describes the procedures and development of the 2016 Mozambican Report Card on Physical Activity for Children and Adolescents. Methods: Following the procedures adopted in 2014 for that year's report card, comprehensive searches on new data related to indicators of physical activity (PA) were done. A committee composed of physical activity and sports specialists graded each indicator consistent with the process and methodology outlined by the Active Healthy Kids Canada Report Card model. Results: Nine indicators of PA were graded. Compared with 2014 there were several differences which were caused by changes in the country as well as a more effective evaluation from the committee. The following grades were assigned: Overall Physical Activity Levels, $C$; Organized Sport Participation, $F$; Active Play, $D$; Active Transportation, $C$; Schools, D; Community and the Built Environment, $F$; and Government, $F$. Sedentary Behaviors and Family and Peers were graded Incomplete due to the lack of available information. Conclusion: The decline of the PA habits in urban centers reported in 2014 are accentuated and is influencing the rural areas in several ways. At present, there is no strategy or effective action from authorities to reverse this negative trend.
\end{abstract}

Keywords: public health, play, sport, sedentary behavior, policy

The first Mozambican Report Card on Physical Activity for Children and Adolescents was published in 2014. ${ }^{1}$ At the time, we observed a relevant gap physical activity behaviors between rural and urban areas. Although traditionally very active, ${ }^{2,3}$ urban centers have rapidly evolved with changes to both the built and social environments that promote inactivity and sedentarism, with the health-related consequences. ${ }^{4,5}$

Although the 2014 Mozambican Report Card is recent, urbanization in Africa, and particularly in Mozambique, is a very fast process that is changing the epidemiological landscape of the country very quickly. ${ }^{6}$ These changes have an important impact on public health and calls for attentive, permanent surveillance to inform strategies and actions to preserve and promote population health. Thus, the 2-year gap since the last report card evaluation seems to be appropriate to encourage authorities and institutions to monitor and promote physical activity (PA).

It was expected that the previous report card evaluation would cause some impact on strategies and action plans, particularly in reversing the urban trend of reduced PA while also improving rural active living. The aims of the present article were to describe the procedures and results of the 2016 Mozambican Report Card and evaluate changes observed since the release of the 2014 report card.

Prista, Daca, Tchonga, Machava, Macucule, and Ribeiro are with the Research Center on Sports Development and Physical Activity, Universidade Pedagógica (Pedagogic University), Maputo, Mozambique . Prista, Daca, and Ribeiro are also with the Faculty of Physical Education and Sports Science, Universidade Pedagógica, Maputo, Mozambique . Tchonga is also with the School of Sports Sciences, Eduardo Mondlane University, Maputo, Mozambique. Prista (aprista1@gmail.com) is corresponding author.

\section{Methods}

The 2016 Mozambican Report Card was developed by the Research Group for Physical Activity and Health (NIAFS), which is located in the Research Center for Sports and Physical Activity (CIDAF) within the Universidade Pedagógica of Mozambique. The report card working group consisted of 6 members who included researchers and postgraduate students in the fields of sport and PA; all were professionals actively involved with PA and sport.

As in 2014, the Mozambique Report Card followed the procedures developed by Active Healthy Kids Canada and promoted by the Active Healthy Kids Global Alliance (www.activehealthykids. org). ${ }^{7}$ As described in these procedures, grades ranged from $A$ to $F$ according to what is the consensus for the percentage of children that are succeeding in PA in each respective category $(A=\geq 80 \%$; $B=60 \%$ to $79 \% ; C=40 \%$ to $59 \% ; D=20 \%$ to $39 \% ; F \leq 20 \%$ ). An Incomplete (INC) grade was assigned to indicators that were lacking sufficient data to assign a letter grade.

The first step in the report card development involved the collection and collation of all new research and surveillance information for the years 2014-2016. All members of the committee were involved in data collection and synthesis as well as in direct contact with governmental institutions and nongovernmental organizations.

The team at various levels identified and synthesized key articles, designed and produced the final report card, and developed an uptake strategy including media engagement. Data sources included peer-reviewed journal publications, presentations at peer-attended forums, unpublished graduate student theses, and data from other organizations and agencies such as government ministries and departments including the National Institute of Statistics, Ministry of Education, Ministry of Health, Ministry of Youth and Sport, and National Institute of Sports. 
Due to a paucity of published information on PA and body weight of Mozambican children and youth, the report card writing group unanimously agreed to use both questionnaires and interviews to generate the required information. As such a previously developed an objective questionnaire which informed the development of the Mozambique 2014 report card was used to inform the 2016 report card. The questionnaire was based on the report card categories and it was composed by a previous explanation of the report card goals and procedures and a request to the institution or the individual to give his opinion about the grade that should be attributed to each category, including the fundamentals and objective data that supports the grade suggested. A total of 24 researchers and sport specialists, as well as 11 official institutions were selected using the snowball method of sampling. All institutions, at a national level, with expertise and experience in sports and PA for children were therefore sampled: Ministry of Youth and Sports, Ministry of Education and Hyman Development, Ministry of Health, National Institute of Sports, National Sports Promotion Fund, National Olympic Committee, National Institute of Statistics, National Institute of Education, National Institutes of Health, Faculty of Physical Education and Sports, and the Faculty of Medicine.

Researchers and sports specialists who completed the questionnaire represented academic disciplines within Mozambique. A total of 24 were identified and contacted. Where clarity was required, the research team provided verbal explanation.

Information and data was gathered for the following PA indicators: Overall Physical Activity Levels, Organized Sport Participation, Active Play; Active Transportation, Sedentary Behaviors, Family and Peers (infrastructure, support, parental/peer behaviors), School (infrastructure, policies and programs), Community and the Built Environment (infrastructure, policies, programs, safety), Government and Nongovernment (strategies, policies, investments), and Body Composition were collected and analyzed. Evidence regarding the promotion of healthy active lifestyle was considered to inform potential initiatives and programs at home, at school, and in the community, aimed at promoting active and healthy lifestyles for Mozambique children and youth.

Only 1 institution had objective data. Nine individuals completed the questionnaire and 12 persons participated in the consensus discussion. A meeting was organized to discuss and interpret the available evidence and responses from the questionnaire, and establish consensus for the final report card grades. By consensus, and based on the best available evidence, grades were assigned to each PA indicator in accordance with the grading scheme and benchmarks used previously. ${ }^{8}$ Field knowledge of the expert panel were recognized has an important and credible source of information.

\section{Results and Discussion}

The 2016 Mozambican Report Card on Physical Activity for Children and Adolescents maintained the 9 indicators of PA suggested. The grades assigned to each indicator are summarized in Table 1.

There were several changes from the 2014 grades. Compared with the 2014 report card, it is noted that 5 indicators got lower grades in 2016.These included Overall Physical Activity Levels, Active Play, Active Transportation, School, and Government. Organized Sport Participation and Community and the Built Environment did not change, while, as in 2014, no grades were assigned to Sedentary Behaviors and Family and Peers due to the lack of evidence.

The cover of the Mozambican Report Card is illustrated in Figure 1 .

As indicated in the previous report card, ${ }^{1}$ the major limitation to this process was the lack of quality representative data. Despite this lack of information, the data available confirmed what is considered the main factor affecting PA in African countries (ie, the trend for a rapid urban growth). Moreover, the gap between rural and urban areas, although still very large, is characterized by changes in rural areas that seem to be slowly adopting urban habits.

In general, observed changes in the infrastructure and services may be causing a shift in some activity behaviors. ${ }^{9}$ For example, electricity was used by $13.9 \%$ of the population in $2008,20.0 \%$ in 2011 , and $24.8 \%$ in 2015; and ready access to safe water increased from $40.5 \%$ to $50.9 \%{ }^{10,11}$ Similarly, bicycle use has been reduced in both rural and urban centers, while motorcycle has increased more than twice in rural areas. ${ }^{11}$ Thus, the increased ownership and use of cell phones, motorized transport and other labor saving electrical devices in rural areas is evident and may cause significant changes in activity levels. ${ }^{11}$

In the 2014 report card we postulated that children and adolescents from the rural area population have a role in the daily household chores and agriculture and spend their free time in active outdoor games because there is no TV and video games in rural areas. ${ }^{12}$ Although still partially true, the "invasion" of technology

\begin{tabular}{lcc}
$\begin{array}{l}\text { Table } \mathbf{1} \\
\text { Cards }\end{array}$ & Summary of Grades From the $\mathbf{2 0 1 4}$ and $\mathbf{2 0 1 6}$ Mozambican Report \\
\hline Indicator & $\mathbf{2 0 1 4}$ & $\mathbf{2 0 1 6}$ \\
\hline Overall Physical Activity Levels & $B$ & $C$ \\
Organized Sport Participation & $F$ & $F$ \\
Active Play & $C$ & $D$ \\
Active Transportation & $B$ & $C$ \\
Sedentary Behaviors & $I N C$ & $I N C$ \\
Family and Peers & $I N C$ & $I N C$ \\
School & $C$ & $D$ \\
Community and the Built Environment & $F$ & $F$ \\
Government & $C$ & $F$ \\
\hline
\end{tabular}

Note. The grade for each indicator is based on the percentage of children and youth meeting a defined benchmark: $A$ is $81 \%$ to $100 \% ; B$ is $61 \%$ to $80 \%$; $C$ is $41 \%$ to $60 \%, D$ is $21 \%$ to $40 \% ; F$ is $0 \%$ to $20 \%$; INC is Incomplete data. 


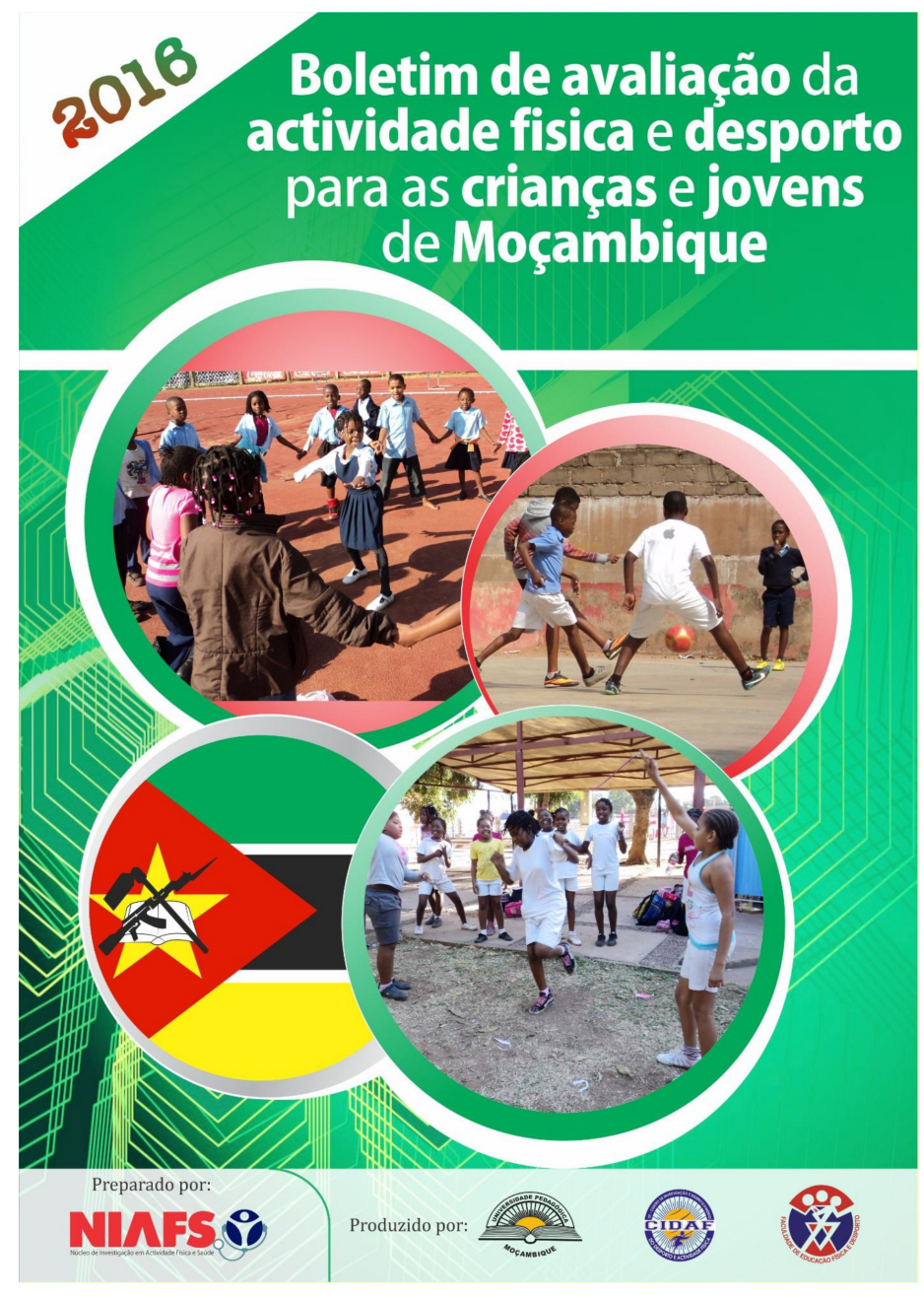

Figure 1 - Front cover of 2016 Mozambique Report Card.

maybe influencing children and adolescent habits, even in rural areas. For example the possession in rural areas of cellular phones changes, between 2008 and 2015, from $11.5 \%$ to $45.6 \%$. This may have an impact on free time activities, including walking and playing outdoors which used to have an important impact on the activity levels of this population. ${ }^{2}$ Thus, it seems that during the last 2 years there were environmental and socio demographic changes that affected PA activity habits.

\section{Overall Physical Activity Levels: C}

Overall Physical Activity Levels was assigned a $C$ grade. Studies from the last 2 decades have shown that the overall PA levels were very high but have decreased in the urban centers for the last decade. ${ }^{13}$ The high levels of PA were attributed to subsistence activities, such as pounding grain and carrying water, walking relatively long distances to school and/or to water sources, as well as routine participation in active outdoor games. ${ }^{12}$ This high level of activity was confirmed in the previous report card prepared in 2014, in which overall PA levels of Mozambican children and youth were among the highest in 15 African and non-African countries that participated in the study. ${ }^{8}$
Recent data show a dramatic trend toward a reduced amount of activity. Secular trend data on PA in urban Mozambican school aged children and adolescents compared PA levels of the Maputo population between 1992 and 2012 and were published recently. ${ }^{13}$ Adverse trends in time spent in households, playing active games and walking contributed significantly to a reduction in PA in both boys and girls.

Another recent study with a sample of 1097 10- to 12-year-old children from both genders (data not published) compared urban, peri-urban, and rural children aged 10 to 12 years using pedometers worn for 1 week. These data demonstrate that only $36.8 \%$ of the boys and $19.9 \%$ of the girls completed more than 60 minutes per day of moderate-to-vigorous physical activity (MVPA). The percentages were higher in rural areas but still more than one-half of the children did not reach the 60 minutes of MVPA target.

Evidence indicates that the percentage of children that perform the recommended PA levels is declining. The growth of the urban centers and the adoption of some urban behaviors by rural children, such as spending time in new communications technology and using motorized transportation, were among the causes attributed to this result. In addition, it seems that there is a shift from agriculture to trading in the occupational data in both urban and rural areas, which may also contribute to reduced PA levels. All these data appear to confirm the decrease in overall PA levels, relative to the 2014 report.

Finally, accelerometer data (data not published) comparing Mozambican children with Europeans peers suggest a preference for light activities rather than MVPA. This preliminary observation requires more research. In summary, the Report Card Committee concluded that less than $60 \%$ of the children in the country are now sufficiently active, which justifies the grade $C$ for this indicator.

\section{Organized Sport Participation: $\boldsymbol{F}$}

Organized Sport Participation was again assigned an $F$ grade. In the last 2 years no change in this item has been observed. Participation at the club level, as well as access to sports clubs, continues to be very limited. Although no formal and official statistics are available, it is well known, and experts agreed, that very few children participate in any form of regular basis organized sports. Based on this assumption, and despite the lack of objective information, the consensus in attributing a grade in this category was achieved.

\section{Active Play and Leisure: $\boldsymbol{D}$}

In the 2014 Mozambican Report Card, the Active Play and Leisure indicator was graded a $C$, taking into consideration the available literature. The grade was based on data that showed that the prevalence of regular outdoor play was over $80 \%$ in rural areas and $57 \%$ among school youth in urban areas. ${ }^{14}$ The abovementioned factors that affected overall PA in both urban and rural areas affected this item. In urban centers space for PA continues to be reduced ${ }^{5}$ and secular trend data show this continued decline. ${ }^{13}$ Observation of rural areas suggested that, although still higher than in urban settings, the spontaneous active games are reducing significantly. Due to this adverse secular trend for physical inactivity, and on the basis of the best available evidence, the Report Card committee changed the grade to a $D$.

\section{Active Transport: $C$}

New studies related to the Active Transport indicator have observed some changes in the way that children move between places. The 
Mozambique site of a multicenter research project ${ }^{15}$ collected data on 1097 children from both urban and rural areas (not published). The proportion of subjects that walked to school was $45.8 \%$, but the differences were very high between urban (12.5\%) and rural $(95.5 \%)$ children. Although the majority of the population still lives in rural areas, migration to cities and transformation of rural places and small villages toward an urban lifestyle is threatening the traditional active way of life. The trend to motorized transport is evident. Data show that the use of motorized transport in rural areas has grown almost 3 -fold in the last 8 years and increased to $2 \%$ of the total expenses for a family. ${ }^{11}$ In the same period the possession of bicycles has been reduced by $5 \%$ in both urban and rural areas. ${ }^{11}$

Further impacting on active transportation, is the apparent growth of taxi services, including motorcycle, car, and mini-bus services and school buses that are readily available. Perceived lack of security related to crime and sidewalk overcrowding, may be at least partially responsible for these trends in active transport. Collectively, it is evident that the use of active transport is declining in children which caused a decrease in grade from $B$ to $C$.

\section{Sedentary Behavior: INC}

Due to the lack of data no grade could be assigned to this indicator, similar to the 2014 report card. However, expert opinion recognized that there has been a substantial increase in sedentary habits. First, the growth and availability of the internet is impacting children and adolescents. Second, there has been a shift from familiar agriculture to small trading that includes children and increases sedentary time. Unfortunately, there are presently no objective data that can estimate the amount of sedentarism. This is a priority for future research.

\section{Family and Peers: INC}

As in the 2014 Mozambican Report Card, no data were available to inform this indicator. However, there are anecdotal reports that Mozambican parents, families, and peers tend to encourage PA. The validity and extent of this impression cannot be measured since there are no studies or reports about the topic.

\section{School: $D$}

Physical education (PE) continues to be mandatory from 1st through 12 th grade, with (theoretically) ${ }^{16,17} 2$ classes a week, often combined in a single day. Resources continue to be very limited and quality of the classes continues to be low, as reported in $2014 .^{1}$

There is a lack of objective data to thoroughly inform this indicator. Although there is a national guideline for PE classes, it is well known that the large majority of the schools have no active policy and a very low percentage of the students have 150 minutes per week of physical education or sports activities.

Considering that nothing was done to improve the percentage of students that practice regular exercise and sports at schools contrasting to the increase of number of schools and students that turns the percentage even lower, the grade attributed for this indicator was $D$.

\section{Community and the Built Environment: $\boldsymbol{F}$}

As emphasized in the 2014 report card, the practice of PA is primarily related to subsistence activities, particularly in rural areas of the country. The encroachment of the built environment and urban development on public and private space previously dedicated to traditional recreational activities and sports, has increased, despite all efforts by civil society to reverse this trend. ${ }^{5,18}$ Very few municipalities have a program to promote PA including activities and infrastructures. Based on expert opinion, the questionnaire results and observation the percentage of children that have access to playgrounds and sports facilities is extremely low and so this indicator was graded $F$.

Looking at the international data it seems clear that the investment on the built environment is related to socioeconomic development. Countries from Europe, America, and Oceania were graded from $A$ to $C$, while African and Latin American were graded $D$ or $I N C .{ }^{8}$ This brings the idea that the development of a heathy environment is associated with a condition of economic development. Knowing that even developed countries have remarkable public health problems associated with the environment, we may suggest from the existing report card data in the literature that economic development is a necessary but not sufficient condition for a healthy built environment.

\section{Government: $\boldsymbol{F}$}

The polices and regulations intended to promote participation in PA and sport exist but they are not typically translated into action or implemented. ${ }^{19-21}$ Although there is no opposition to PA and sport practice, there is no strategy or plan to promote PA and practice of sports by children. Moreover, there is a complete lack of data from the official authorities regarding the promotion of PA. It becomes very clear for the panel of experts that there is a complete inexistent of a plan and action. Taking this into consideration, it was decided to lower the grade to $F$.

\section{Limitations}

The general lack of information to inform the grades for each indicator was the main limitation of this process. There is a lack of surveillance related to PA and sports and the majority of the data come from few research studies. There is no structural information system for PA and sports. Thus, as with the 2104 Mozambican Report Card, ${ }^{1}$ grades were attributed mainly by consensus using those few research, that were not representative of the whole country, and the experience of the members who participated in this work. Nevertheless, the report card is believed to be a useful catalyst to encourage the promotion of PA and research in this area.

\section{Conclusion}

In conclusion, the declining level of habitual PA in urban centers reported in 2014 appear to be progressing and are beginning to influence the rural areas in several ways that may adversely affect public health. Authorities are encouraged to develop and implement strategies and policies to preserve healthy active living behaviors and reverse this negative trend in an effort to promote the health of the Mozambican population.

\section{References}

1. Prista A, Picardo S, Ribeiro E, Libombo J, Daca T. Results From Mozambique's 2014 report card on physical activity for children and youth. J Phys Act Health. 2014;11(Supp 1):S79-S82. PubMed doi:10.1123/jpah.2014-0179

2. Prista A, Marques A, Maia J. Relationship between physical activity, socioeconomic status and physical fitness of 8-15 year old youth 
from Mozambique. Am J Hum Biol. 1997;4(9):449-457. doi:10.1002/ (SICI)1520-6300(1997)9:4<449::AID-AJHB4>3.0.CO;2-R

3. Nhantumbo L, Maia J, Saranga S, Prista A. Physical activity among children and adolescents in a rural community in Mozambique: effects of age, sex, and nutritional status. Rev Panam Salud Publica. 2008;23(3):171-178. PubMed

4. Padrão P, Damasceno A, Silva-Matos C, Prista A, Lunet N. Physical activity patterns in Mozambique: urban/rural differences during epidemiological transition. Prev Med. 2012;55(5):444-449. PubMed doi:10.1016/j.ypmed.2012.08.006

5. Prista A, Magaia S, Silva-Matos C, Damasceno A. Saúde, estilo de vida e urbanização em Moçambique: problemas e perspectivas. Revista Moçambicana de Ciências de Saúde. 2014;1:11-21.

6. http://www.afdb.org/en/blogs/afdb-championing-inclusive-growthacross-africa/post/urbanization-in-africa-10143. Accessed on May 25, 2016.

7. Colley R, Brownrigg M, Tremblay M. A model of knowledge translation in health: the Active Healthy Kids Canada report card on physical activity for children and youth. Health Promot Pract. 2012;13(3):320-330. PubMed doi:10.1177/1524839911432929

8. Tremblay M, Gray C, Akinroye K, et al. Physical activity of children: a global matrix of grades comparing 15 countries related to the physical activity of children. J Phys Act Health. 2014;11(suppl.1):S113-S125. PubMed doi:10.1123/jpah.2014-0177

9. IndexMundi. http://www.indexmundi.com/mozambique/ . Assessed May 22, 2016.

10. Ministério da Saúde (MISAU), Instituto Nacional de Estatística (INE) e ICF International (ICFI). Moçambique Inquérito Demográfico e de Saúde 2011. Calverton, Maryland, USA: MISAU, INE e ICFI.

11. Instituto Nacional de Estatística (INE) 2015. Relatório final do inquérito ao orçamento familiar - IOF-2014/15

12. Saranga S, Prista A, Nhantumbo L, Manasse S, Seabra A, Maia J. Alterações no padrão de actividade física em função da urbanização e determinantes socio-culturais: um estudo em crianças e jovens de Maputo (Moçambique). Revista Brasileira de Ciência e Movimento. 2008;16(2):17-24.

13. Dos-Santos F, Maia J, Gomes T, et al. Secular trends in habitual physical activities of Mozambican children and adolescents. Int J Environ Res Public Health. 2014;11(10):10940-50. PubMed doi:10.3390/ ijerph111010940

14. Nhantumbo L, Saranga S, Seabra A, Maia J, Prista A. Aptidão física e actividade física em populações africanas: uma revisão da literatura. Revista Portuguesa de Ciências do Desporto. 2006;6(3):373-400. doi:10.5628/rpcd.06.03.373

15. Onywera V, Akinroye K, Larouche R, Oyeyemi A, Prista A, Tremblay M. Assessment of physical activity and active transport among school children in eastern, western and southern regions of Africa: the case of Kenya, Nigeria, and Mozambique. Research Project, Kenyata University, Nairoby. 2013

16. Instituto Nacional d Educação (INDE) e Ministério da Educação e Desenvolvimento (MINED) 2003. Plano Curricular do Ensino Básico. Maputo, Moçambique.

17. Instituto Nacional de Educação (INDE) e Ministério da Educação e Cultura (MEC) 2006. Plano Curricular do Ensino Secundário Geral. Maputo, Moçambique.

18. Petição Publica: Por um crescimento urbano que garanta a qualidade de vida dos munícipes de Maputo 2015. http://peticaopublica.com/ pview.aspx?pi=PT73606. Accessed May 25, 2016.

19. Diploma Ministerial n ${ }^{\circ} 24 / 99$ de 24 de Março aprova o Regulamento do desporto escolar

20. Southern African Development Community (SADC). Resolução 1/2002 de 14 de Fevereiro, ratifica o Protocolo da SADC sobre a cultura, informação e o Desporto.

21. Ministério de Educação e Desenvolvimento (MINED). Regulamento Geral de Educação Física e Desporto. Maputo, Mozambique. 1994. 